1 | P a g e

Revised Manuscript submitted to Applied Catalysis A: General

Type of paper: Research Paper

\title{
Copper Ferrite Spinel Oxide Catalysts for Palm Oil Methanolysis
}

\section{Chuleeporn Luadthong, Pongtanawat Khemthong, Waraporn Nualpaeng,}

\author{
Kajornsak Faungnawakij*
}

National Nanotechnology Center (NANOTEC), National Science and Technology Development

Agency (NSTDA), 111 Thailand Science Park, Paholyothin Rd., Klong Laung, Pathumthani 12120, Thailand

* Corresponding author: Tel.: +66 25647100 ext 6638, Fax: +66 2564 6981, E-mail address: kajornsak@nanotec.or.th (K. Faungnawakij). 


\begin{abstract}
Copper ferrite spinel oxide $\left(\mathrm{CuFe}_{2} \mathrm{O}_{4}\right)$ samples with calcination temperatures ranging from 500$900{ }^{\circ} \mathrm{C}$ were synthesized using the sol-gel combustion method with citric-nitrate precursors. Each calcined sample was further characterized and carefully analyzed for its structure, morphology, porosity, magnetic property and reducibility. For the first time, the catalytic performance of the ferrite spinels was examined for palm oil methanolysis. The characterization results from X-ray diffraction (XRD), extended X-ray absorption fine structure (EXAFS) and Xray absorption near edge structure (XANES) analyses revealed that the major part of the active species was divalent ions of $\mathrm{Cu}^{2+}$ and $\mathrm{Fe}^{2+}$ and that they played a crucial role in the activity of the considered spinel catalysts. The catalytic behaviors strongly depended on the crystallinity of spinel structures and operating parameters, such as the catalyst loading and methanol to oil molar ratio. The $\mathrm{CuFe}_{2} \mathrm{O}_{4}$ calcined at $700{ }^{\circ} \mathrm{C}$ was the most active and selective for methanolysis with palm oil. No activity decline was observed over the catalyst after it was reused for 5 cycles without any post-treatment. Easy and effective catalyst separation could be obtained when magnetization was applied to the magnetic spinel catalysts.
\end{abstract}

Keywords: Fatty acid methyl ester, Methanolysis, Copper ferrite spinel oxide, sol-gel combustions, XAFS 


\section{Introduction}

Biodiesel is among the important alternative transportation fuels in use today. It has been used by blending it with a petroleum-based fuel to be used in a diesel engine. The combustion of this blend is expected to generate low-toxicity compounds (CO, NOx) and reduce greenhouse gases $\left(\mathrm{CO}_{2}\right)$ compared to traditional fossil fuels. Currently, biodiesel is industrially produced through triglyceride transesterification with methanol or ethanol in the presence of soluble alkali $\mathrm{NaOH}$ or $\mathrm{KOH}$ catalysts. This process can achieve FAME contents higher than $98 \%$ within 30 minutes under a mild condition of $60-65{ }^{\circ} \mathrm{C}[1,2]$. However, the disadvantages of using alkali solution catalysts are waste water generation, poor quality of the glycerol by-product and soap formation [3]. More importantly, it is hard to recover the catalyst from the reaction media. Therefore, heterogeneous catalysts have been developed to overcome these limitations [4-6]. The alkaline earth oxides and methoxides have been widely developed for heterogeneous transesterification; however, their lack of stability is a reason to imagine new heterogeneous catalysts [4]. Stern and co-workers reported that the spinel mixed oxide of $\mathrm{Al}$ and $\mathrm{Zn}$ was active as a potential catalyst when operated at a reaction temperature of $200{ }^{\circ} \mathrm{C}$ and 60 bars of pressure [7]. The first heterogeneous catalyst industrial process was revealed by the French Institute of Petroleum (IFP) using $\mathrm{ZnAl}_{2} \mathrm{O}_{4}$ at a reaction temperature of $180-220{ }^{\circ} \mathrm{C}$ and $30-80$ bars of pressure in 2005 [8]. In this regard, there has been increasing interest in the use of spinel catalysts as heterogeneous catalysts for biodiesel production. Many research groups, those of including Pugnet [9] and Alves [10], have described that the activity of spinel $\mathrm{ZnAl}_{2} \mathrm{O}_{4}$ for the transesterification of vegetable oil can achieve approximately 80\% FAME content at reaction temperature of $200{ }^{\circ} \mathrm{C}$ and methanol:oil ratio of $27: 1$, and $>95 \%$ FAME content with reaction temperature above $150{ }^{\circ} \mathrm{C}$ and methanol: oil ratio of $40: 1$ in a batch reactor. More recently, 
Sankaranarayanan and co-workers discovered that spinel-type mixed oxides prepared by coprecipitation were active for the transesterification of cooking oil and Jatropha oil [11]. The results indicated nearly $100 \%$ of triglyceride conversion and $100 \%$ selectivity of the FAME content within 10 hours at a reaction temperature of $180^{\circ} \mathrm{C}$. It should also be considered that the application of the spinel catalysts can advance the recovery process due to their magnetic property [12-14].

The use of heterogeneous catalysts with specific magnetic properties for biodiesel production via transesterification would be improved by the rapid and easy separation after applying an external magnet. Among the many magnetic spinel oxide catalysts, copper ferrite $\left(\mathrm{CuFe}_{2} \mathrm{O}_{4}\right)$ is an interesting material due to its unique properties, such as its good catalytic activity, high thermal stability and superior magnetization. $\mathrm{CuFe}_{2} \mathrm{O}_{4}$ has been explored for its high catalytic performance in applications such as hydrogen fabrication $[15,16]$, gas sensors $[17$, 18], and glycerol hydrogenolysis [19, 20]. Typically, $\mathrm{CuFe}_{2} \mathrm{O}_{4}$ nanoparticles have been prepared by co-precipitation [21], electrospinning [14], mechanical milling [22, 23] and sol-gel methods [24]. The $\mathrm{CuFe}_{2} \mathrm{O}_{4}$ structure is an inverse spinel structure at room temperature, in which eight $\mathrm{Cu}^{2+}$ and eight $\mathrm{Fe}^{2+}$ cations occupy octahedral sites and the other eight $\mathrm{Fe}^{3+}$ are located in the tetrahedral sites [25, 26]. To the best of our knowledge, no comprehensive data are available on $\mathrm{CuFe}_{2} \mathrm{O}_{4}$ for the methanolysis of palm oil, where the $\mathrm{CuFe}_{2} \mathrm{O}_{4}$ samples were used as a promising catalyst in terms of their ease of reuse and separation by applying an external magnetic field.

In this context, magnetic copper ferrite samples were obtained by a sol-gel combustion method using a citric-nitrate precursor route. It has been established that this method could produce the envisaged product with a good homogeneity and low synthetic temperatures [16]. Consequently, this work was intended to elucidate the relationship between the structural 
properties and catalytic activities of catalyst samples. The effects of thermal annealing on the structure with respect to different temperatures were examined, and the samples were further characterized by various techniques for their physicochemical properties. The influences of the catalyst loading, methanol to oil molar ratio and reusability of the catalyst on the biodiesel activity were also investigated.

\section{Experimental}

\subsection{Catalyst Preparation}

The $\mathrm{CuFe}_{2} \mathrm{O}_{4}$ spinel was prepared by a sol-gel combustion method as described elsewhere [20]. Corresponding amounts of one mole of $\mathrm{Cu}\left(\mathrm{NO}_{3}\right)_{2} \cdot 2.5 \mathrm{H}_{2} \mathrm{O}$ (Ajax, 98\%) and two moles of $\mathrm{Fe}\left(\mathrm{NO}_{3}\right)_{3} \cdot 9 \mathrm{H}_{2} \mathrm{O}$ (Ajax, 98\%) were first dissolved in deionized (DI) water at $80{ }^{\circ} \mathrm{C}$ for $2 \mathrm{~h}$. Subsequently, excess citric acid (Ajax, 99\%) as a fuel source was added into the mixture, which was continuously stirred for $1 \mathrm{~h}$. Thereafter, the solution was evaporated at $100{ }^{\circ} \mathrm{C}$ until a dried precursor was obtained. The dried precursor was further combusted at $200{ }^{\circ} \mathrm{C}$. Finally, the combusted catalysts were calcined under an air atmosphere at 500, 700 and $900{ }^{\circ} \mathrm{C}$ for $4 \mathrm{~h}$ with heating rate of $200{ }^{\circ} \mathrm{C} \mathrm{h}^{-1}$ and labelled as CuFe500, CuFe700 and CuFe900, respectively.

\subsection{Catalyst Characterization}

The phase and structure were identified with powder X-ray diffraction (XRD; D8 ADVANCE, Bruker) using $\mathrm{Cu} \mathrm{K} \alpha$ radiation. The instrument was operated at $40 \mathrm{kV}$ and $40 \mathrm{~mA}$ with increments of $0.02^{\circ} \mathrm{s}^{-1}$ and a step time of $0.5 \mathrm{~s}$ over the range of $20^{\circ}<2 \theta<70^{\circ}$. The specific surface area and pore volume were determined by the nitrogen adsorption-desorption 
technique (Nova2000e, Quantachrome Instruments). The pore size distribution was calculated by the Barrett-Joyner-Halenda (BJH) desorption method using the cylindrical pore model. The morphology of the particles was obtained by transmission electron microscopy (TEM; JEM-2100 Jeol). Temperature programmed reduction (TPR) was conducted using a CHEMBET-Pulsar (Quantachrome Instruments). Magnetic hysteresis loops were recorded at room temperature using vibrating sample magnetometry (VSM; LAKE SHORE VSM 7404, Lake Shore Cryotronics) with a maximum magnetic field of $10 \mathrm{kG}$. The degree of metal leaching was evaluated by atomic absorption spectroscopy (AAS; PerkinElmer's PinAAcle 900F). The geometry, oxidation state, and local structural were solved by X-ray absorption spectroscopy (XAS) in the transmission mode. The XAS spectra were collected at the Fe and Cu K-edges on the SUT-NANOTEC-SLRI XAS Beamline (BL-5.2) of the Synchrotron Light Research Institute (Public Organization). Energy calibrations have been carried out with the Fe and Cu metal foils with ring currents of 100-120 mA. A Ge(220) monochromator crystal was used to scan the Xray energy for the spectroscopic data. In the X-ray absorption near edge structure (XANES) region, the step sizes were $0.02 \mathrm{eV}$ with a second of integration time. The extended X-ray absorption fine structure (EXAFS) curve fitting and data reduction were performed using the Athena and EXAFSPAK programs. In addition, the values for the reduction amplitude factor $\left(\mathrm{S}_{0}{ }^{2}\right)$ were not calculated in the fitting. The basic property of the catalyst was evaluated using the temperature-programmed desorption of $\mathrm{CO}_{2}\left(\mathrm{CO}_{2}\right.$-TPD; Quantachrome ChemBET Pulsar Automatic Chemisorption Analyzer). Before $\mathrm{CO}_{2}$ adsorption, the sample was outgassed and purged with helium with at $150{ }^{\circ} \mathrm{C}$ for $60 \mathrm{~min}$. After the saturation of $\mathrm{CO}_{2}$ on the sample, the $\mathrm{CO}_{2}$-TPD was carried out under a helium flow at a flow rate of $30 \mathrm{ml} \mathrm{min}{ }^{-1}$, while the temperature was ramped from room temperature to $900^{\circ} \mathrm{C}$ with a ramping rate of $10^{\circ} \mathrm{C} \min ^{-1}$. 
The acidic property of the catalyst was measured using the temperature-programmed desorption of ammonia combined with the infrared absorption spectrometry and mass spectrometry (IRMSTPD of $\mathrm{NH}_{3}$; MicrotracBEL, Japan). Briefly, the sample was pretreated at $550{ }^{\circ} \mathrm{C}$ under oxygen atmosphere for $2 \mathrm{~h}$, and then cooled down to $100{ }^{\circ} \mathrm{C}$. After the saturation of $\mathrm{NH}_{3}$ on the sample, the measurement was conducted by increasing the desorption temperature from 100 to $530{ }^{\circ} \mathrm{C}$ with a heating rate $2{ }^{\circ} \mathrm{C} / \mathrm{min}$ under a helium flow.

\subsection{Evaluation of catalytic properties}

The methanolysis reactions with $\mathrm{CuFe}_{2} \mathrm{O}_{4}$ catalysts were carried out in a $130 \mathrm{~mL}$ stainless steel autoclave with a magnetic stirrer. In a typical experiment, $10-20 \%$ by weight of $\mathrm{CuFe}_{2} \mathrm{O}_{4}$ catalyst to oil was added into an autoclave containing a mixture of methanol (Carlo Erba Reagenti) and a refined palm olein with molar ratios of 9:1, 13:1 and 18:1. The fatty acid composition of the palm olein is lauric acid (C12:0) 0.4\%; myristic acid (C14:0) 0.8\%; palmitic acid (C16:0) 37.4\%; palmitoleic acid (C16:1) 0.2\%; steraric acid (C18:0) 3.6\%; oleic acid (C18:1) 45.8\%; linoleic acid (C18:2) 11.1\%; linolenic acid (18:3) 0.3\%; arachidic acid(C20:0) 0.3\%; and eicosenoic acid (C20:1) 0.1\%. Then, the reactor was heated to the required temperature $\left(200-220^{\circ} \mathrm{C}\right)$, while the pressure was in a range of 3.0-5.0 MPa. The zero minute of the reaction time was set when the temperature reaches the set point. After completing the reaction, the autoclave was cooled down to ambient temperature in an ice-water bath. The liquid phase was separated by centrifugation and further evaporated to remove the excess amount of methanol. The percent of fatty acid methyl ester (\%FAME) content of biodiesel products was analyzed by gas chromatography (GC-2010, Shimadzu) with a flame ionization detector (FID) using DB-WAX (30 m in length with a $0.25 \mathrm{~mm}$ i.d. and $0.25 \mu \mathrm{m}$ film thickness) as a capillary 
column (Agilent Technologies).Methylheptadecanoate was used as an internal standard for quantification according to the EN14103 standard method. After the first run, each catalyst was recovered by centrifugation and used for the next run without any reactivation to investigate the reusability. The \%FAME content was calculated from GC peak integrations derived in Eq. (1):

$\% F A M E$ content $=\frac{\sum A-A_{E I}}{A_{E I}} \times \frac{C_{E I} V_{E I}}{m} \times 100 \%$

Where $\sum A$ and $A_{E I}$ are the integration peaks of methyl ester $\left(\mathrm{C}_{14}-\mathrm{C}_{24}\right)$ and methylheptadecanoate respectively; $C_{E I}$ is the concentration of methylheptadecanoate; $V_{E I}$ is the volume of methylheptadecanoate; $m$ is the mass of sample. It should be noted that only FAME along with methanol, mono-, di-, and triglyceride were detected in the reaction media.

\section{Result and Discussion}

\subsection{Phase identification}

The distinct phase compounds of the CuFe500, CuFe700 and CuFe900 were observed through the peak intensity and position of XRD patterns (Fig. 1). It is clearly seen that some secondary $\mathrm{Fe}_{2} \mathrm{O}_{3}$ phase was found in the $\mathrm{CuFe} 500$, and those peaks overlapped with the ones corresponding to $\mathrm{CuFe}_{2} \mathrm{O}_{4}$, showing broad peaks and low crystallinity. This result is in good agreement with the data in the literature $[16,27]$. Moreover, it was found that the Cu-containing phase could not be observed in the XRD diffractograms. In contrast, the XRD analysis of CuFe700 and CuFe900 exhibited the well-crystallized phase with unit cell parameters corresponding to a tetragonal lattice (PDF\# 01-072-1174). By evaluating the XRD patterns of CuFe700 and CuFe900, the spectra clearly showed the appearance of tetragonal phase at $2 \theta=$ 
$29.9^{\circ}, 30.8^{\circ}, 34.5^{\circ}, 36.0^{\circ}, 37.2^{\circ}, 41.4^{\circ}, 44.0^{\circ}, 54.1^{\circ}, 55.0^{\circ}, 57.1^{\circ}, 58.2^{\circ}, 62.1^{\circ}$ and $64.1^{\circ}$, which are attributed to the reflections of the (112), (200), (103), (211), (202), (004), (220), (312), (105), (303), (321), (224) and (400) planes, respectively [23].

\subsection{Morphology, pore structures and surface areas}

The specific surface area, pore diameter and total pore volume of the $\mathrm{CuFe}_{2} \mathrm{O}_{4}$ catalyst showed significant decreases with increasing calcination temperatures from 500 to $900{ }^{\circ} \mathrm{C}$, as

shown in Table 1. The surface area decreased from 16.0 to $2.1 \mathrm{~m}^{2} \mathrm{~g}^{-1}$ when the temperature increased from 500 to $700{ }^{\circ} \mathrm{C}$. Similar behaviors were observed with the pore diameter and pore volume. The effect of the temperature became less significant when the temperature increased from 700 to $900{ }^{\circ} \mathrm{C}$. The changes in the properties were ascribable to the sintering effect at high temperature, as confirmed by the TEM image in Fig. 2. The particles of CuFe500 were the smallest in size, whereas the CuFe700 and CuFe900 samples seem to be strongly agglomerated to a large grain size and became a densification of crystallites. It is interesting to note that the spinel grains were enlarged by crystal growth and the sintering of particles when calcined at higher temperature, resulting in a higher crystallinity as well as deceases in the surface area, pore diameter and pore volume.

\subsection{Magnetization property}

Determination of the magnetic field dependence of the magnetization of the calcined $\mathrm{CuFe}_{2} \mathrm{O}_{4}$ catalysts at room temperature was carried out using a VSM with a field range from $\pm 10,000$ Oe. The magnetic hysteresis loops of samples with different calcination temperatures are illustrated in Fig. 3. The magnetic hysteresis loops of calcined $\mathrm{CuFe}_{2} \mathrm{O}_{4}$ samples exhibited a 
perfect deviation from typical "S" shaped ferromagnetic curves at room temperature, which was due to the increasing nanocrystallite size [27].

Obviously, different calcination temperatures affected the magnetic properties of the copper ferrite spinel samples. From the hysteresis curves, the saturation magnetization (Ms) values were $17.89,19.22$, and $23.62 \mathrm{emu} / \mathrm{g}$ for the samples calcined at 500, 700 , and $900{ }^{\circ} \mathrm{C}$, respectively. It should be noted that with increasing crystallite size, the spin order of the existing elements on the surface is predominant, and this corresponds to the affirmation of their magnetic and electrical properties $[2,16]$. It was observed that the catalysts were rapidly separated from the biodiesel product by a small magnet, and the catalyst recovery was completed within a few minutes, as depicted in Fig. 3. These results demonstrated that the efficient separation of the $\mathrm{CuFe}_{2} \mathrm{O}_{4}$ catalysts from biodiesel could be achieved using a magnetic field.

\subsection{Structural analysis with XAFS}

To investigate the electronic and local structures of calcined catalysts, the X-ray absorption fine structure (XAFS) was performed for both the $\mathrm{Cu}$ and Fe elements. The $\mathrm{Cu}$ and $\mathrm{Fe}$ K-edges in the XANES region of the reference compounds are shown in Fig. 4 and Fig. 5, respectively. Prior to the XANES spectra of samples at the Cu K-edge in Fig. 4, it is exhibited that the shape, energy position and white line feature were similar to those of standard $\mathrm{CuFe}_{2} \mathrm{O}_{4}$, and no remarkable pre-edge features appeared. This in turn reveals that $\mathrm{Cu}$ is in the +2 oxidation state and occupies only the octahedral coordination site.

In the case of Fe-coordination compounds, the absorption features of standard $\mathrm{CuFe}_{2} \mathrm{O}_{4}$ and $\mathrm{Fe}_{3} \mathrm{O}_{4}$ show an intense pre-edge with similar centroids at $7113.5 \mathrm{eV}$ attributed to $1 \mathrm{~s} \rightarrow 3 \mathrm{~d}$ electronic transition that is electronic dipole forbidden but quadrupole allowed [28]. It is 
generally seen that this feature is characteristic of the $\mathrm{Fe}^{3+}$ cation in the tetrahedral site [29]. Consequently, a series of Fe K-edges of calcined samples is shown along with $\mathrm{FeO}, \mathrm{Fe}_{3} \mathrm{O}_{4}$, $\mathrm{CuFe}_{2} \mathrm{O}_{4}$ and $\mathrm{Fe}_{2} \mathrm{O}_{3}$ in Fig. 5. The shapes of the spectra were similar for all of the calcined samples. However, the centroid position of the white line peaks of calcined samples reveals a gradual shift to approximately $0.60 \mathrm{eV}$ lower in energy, indicating the existence of Fe ions in the tetrahedral and octahedral sites, which is due to the presence of $\mathrm{Fe}^{2+}$ and $\mathrm{Fe}^{3+}$ oxidation states and agreed with the XRD studies. To identify iron species in the samples, the linear combination fit (LCF) of different spectra was attempted to match the experimental spectrum by summing different percentages of standard spectra. The result is the qualified proportions of different identifiable iron species in samples. The LCF results are tabulated in Table 4. To illustrate the LCF approach, Fig. 6 displays XANES data for the sample with the best-fit combination of standards used in the overlaid fitting. The LCF data provided a mixing fraction of $\mathrm{Fe}^{2+}$ and $\mathrm{Fe}^{3+}$ in the calcined samples. The major phase was $\mathrm{CuFe}_{2} \mathrm{O}_{4}$ along with minor phases of $\mathrm{Fe}_{3} \mathrm{O}_{4}$ and $\mathrm{Fe}_{2} \mathrm{O}_{3}$. Therefore, at maximum calcination, only the spinel of iron oxides was obtained. It should be pointed that XANES analyses could provide unique information of unknown phases and about the formation of metastable, intermediate and disordered phases toward the formation of Fe oxide species, which explains why they were not observed by XRD [30]. The EXAFS analyses were also performed to complement the results obtained from XANES studies. The experimental and theoretical EXAFS function on $k$-space and their Fourier transforms in $R$-space for the calcined samples are illustrated in Fig. 7. The corresponding structural parameters are listed in Table 3. In the evaluation of the EXAFS results, analysis of the first peak exhibits two distinct Fe-O shells at approximately 1.9 and $2.0 \AA$ in tetrahedral and octahedral sites, respectively. It was found that the second peak is broad and overlapped a wide range, resulting in 
the existence of the second and third shells. Because the results indicated the presence of Fe atoms in both the tetrahedral and octahedral sites, the $\mathrm{Cu}$ atoms occupy only the third shell in the octahedral site, and their occupancy could not be validated in the tetrahedral site, which agrees with the XANES results. Using these values, the interatomic distance of the Fe-O bond decreases with increasing calcination temperatures. However, the interatomic distance of the Fe-Fe bond was not different for each calcination temperature.

\subsection{Catalytic performance}

The catalytic activity was evaluated for the transesterification of palm olein oil. Prior to the catalytic testing, a blank test without catalyst was carried out under these conditions: methanol/oil molar ratio of 9:1 at a $200{ }^{\circ} \mathrm{C}$ reaction temperature for $3 \mathrm{~h}$, yielding a FAME content of $16.1 \%$. The biodiesel product from the catalyst calcined at $500{ }^{\circ} \mathrm{C}$ was not analyzed because a dark green solution was obtained that resulted from a catalyst degradation. The FAME content was achieved at 54.6 and $33.8 \%$ for the catalysts calcined at 700 and $900{ }^{\circ} \mathrm{C}$, respectively. According to the results, it can be concluded that the decrease in the catalytic activity occurred when the catalyst was calcined at higher temperature. This suggested that a good copper ferrite catalyst could possess a small crystallite size with a high surface area and pore volume. Thus, the calcination temperature should not be greater than $700{ }^{\circ} \mathrm{C}$. The degree of ion leaching was quantified by the AAS technique. The CuFe500 catalyst provided the highest degree of $\mathrm{Cu}^{2+}$ and $\mathrm{Fe}^{3+}$ leaching compared to the other catalysts. The degree of leaching of the $\mathrm{Cu}^{2+}$ and $\mathrm{Fe}^{3+}$ decreased with increasing the calcination temperature from 500 to $900{ }^{\circ} \mathrm{C}$, as shown in Table 3. Interestingly, these leaching ions might be coming from the metaphase and/or disordered phase of $\mathrm{Fe}_{2} \mathrm{O}_{3}$ and $\mathrm{Fe}_{3} \mathrm{O}_{4}$, as indicated by the XANES technique. However, a small amount of $\mathrm{Cu}$ ions was also observed, possibly due to the re-dissolving during the reaction. 
Considering the leaching problem and catalytic activities of these three catalysts, CuFe700 was selected for further investigation. The CuFe700 spinel catalyst was soaked in methanol at $200{ }^{\circ} \mathrm{C}$ for $3 \mathrm{~h}$, and then the solid catalyst was removed from the methanol. The transesterification test was then carried out using the resultant methanol and palm oil. It turned out that the FAME content was comparable to that obtained from the blank test. Therefore the homogeneous transesterification catalyzed by the possible leaching species was insignificant. As shown in the Supplementary Material, $\mathrm{NH}_{3}$-TPD result suggested that no acidity was found on the catalyst, while a small amount of basic site of $54 \mu \mathrm{mol} / \mathrm{g}$ was observed as evidenced by $\mathrm{CO}_{2}$-TPD. The acidity of the spinel is relatively low as compared with that of $\mathrm{CaO}(1547 \mu \mathrm{mol} / \mathrm{g}$ [31] or $\mathrm{SrO}$ (3700 $\mu \mathrm{mol} / \mathrm{g}$ [32]) which is highly active for the transesterification at $60-65{ }^{\circ} \mathrm{C}$. Therefore the transesterification over the spinel is considered to proceed via base-catalyzed mechanisms at the high temperature. The high loading of the catalyst and high reaction temperature are required due to the low acidity of the spinel.

The influence of the catalyst loading on the transesterification of palm olein oil was also examined over 10 and 20\% CuFe700 catalyst loading under these conditions: methanol/oil molar ratio of 9:1 at a reaction temperature of $200{ }^{\circ} \mathrm{C}(\mathbf{F i g} . \mathbf{8})$. The results revealed that the presence of a high catalyst loading could enhance the FAME content in short reaction times (within 6 h). This could be described as follows: a large amount of the catalyst provided more active sites and led to the initiation of catalytic activity in a short reaction time. However, for reaction times longer than $6 \mathrm{~h}$, the increase in the catalyst loading had no effect on the FAME content. The maximum FAME content reached 81\% for both catalysts within 7 h. Even when the reaction temperature was increased to $220{ }^{\circ} \mathrm{C}$ with $20 \%$ catalyst loading, a small increase in the FAME content of approximately $2 \%$ was obtained. 
The transesterification is an equilibrium reaction that requires a large excess of alcohol or removal of the glycerol produced in order to achieve a $100 \%$ yield of biodiesel. Therefore, the molar ratio of alcohol to oil is one of the important factors that influence the production of biodiesel. The influence of the molar ratio of methanol and oil was evaluated at 9:1, 13:1 and 18:1 (Fig. 9) with a catalyst loading of $20 \%$ at a reaction temperature of $220{ }^{\circ} \mathrm{C}$ for $7 \mathrm{~h}$. The results revealed that the FAME content was slightly increased with increasing the methanol to oil molar ratio. The maximum FAME content of $90.7 \%$ was reached when using the $18: 1$ molar ratio of methanol and oil. This result agrees with reports on biodiesel production, which indicated that excess amounts of methanol can enhance the miscibility of reactants and the rate of the transesterification reaction over a heterogeneous catalyst [31].

\subsection{The study of reusability}

One of the key advantages of heterogeneous catalysts is the reusability and recovery of the catalyst. The reusability of the catalyst can also reduce the operating costs. To evaluate the reusability, the CuFe700 was spent at $200{ }^{\circ} \mathrm{C}$ for $7 \mathrm{~h}$ with a catalyst loading of $20 \%$ and a methanol/oil molar ratio of 9:1. After completing the reaction, the spent catalyst was recovered by centrifugation, dried in air and used without any further treatment. The results are presented in Fig. 8. The FAME content was retained after repeating 5 cycles, confirming that the catalyst is highly stabile without the loss of activity.

\section{Conclusions}

Copper-ferrite spinel catalysts have been developed for the heterogeneous transesterification of palm olein oil to biodiesel. The calcination temperature played a crucial role in determining the catalyst properties. The X-ray analysis results demonstrated that the 
major part of the active species was divalent ions of $\mathrm{Cu}^{2+}$ and $\mathrm{Fe}^{2+}$, which played a significant role in the activity. Leaching and the dissolution of the spinel was observed over the catalyst with a low degree of crystallization calcined at $500{ }^{\circ} \mathrm{C}$, while the high calcination temperature of $900{ }^{\circ} \mathrm{C}$ gave insufficient surface area for the reaction. $\mathrm{CuFe}_{2} \mathrm{O}_{4}$ calcined at $700{ }^{\circ} \mathrm{C}$ having tetragonal spinel phase with excellent crystallinity and good ferromagneticity was the most active catalyst without any deactivation under the testing conditions. High FAME contents (above $90 \%$ ) were obtained using a methanol:oil molar ratio of $18: 1$ at $220{ }^{\circ} \mathrm{C}$ for $7 \mathrm{~h}$.

\section{Acknowledgements}

The authors acknowledge the financial support from the National Nanotechnology Center, NSTDA, Thailand and the Thailand Research Fund (TRF) to K.F. (RSA5580055). This research was also supported by Collaboration Hubs for International Program (CHIRP) of Strategic International Collaborative Research Program (SICORP), Japan Science and Technology Agency (JST) and the JASTIP program-WP2 (NSTDA-Kyoto University collaboration). 


\section{References}

[1] F. Ma, M.A. Hanna, Bioresource Technology, 70 (1999) 1-15.

[2] A. Sivasamy, K. Y. Cheah, P. Fornasiero, F. Kemausuor, S. Zinoviev, S. Miertus, ChemSusChem, 2 (2009) 278-300.

[3] M. D. Serio, R. Tesser, L. Pengmei, E. Santacesaria, Energy \& Fuels, 22 (2008) 207-217.

[4] A. L. de Lima, C. M. Ronconi and C. J. A. Mota, Catalysis Science \& Technology, 2016, DOI: 10.1039/C5CY01989C.

[5] A.M. Ruhul, M.A. Kalam, H.H. Masjuki, I.M.R. Fattah, S.S. Reham, M.M. Rashed, RSC Advances, 5 (2015) 101023-101044.

[6] S.H. Teo, Y.H. Taufiq-Yap, U. Rashid, A. Islam, RSC Advances, 5 (2015) 4266-4276.

[7] R. Stern, G. Hillion, J. J. Rouxel and S. Leporq, US patent application, 1999/5908946 A. Process for the production of esters from vegetable oils or animal oils alcohols.

[8] L. Bournay, G. Hillion, P. Boucot, J. A. Chodorge, C. Bronner and A. Forestiere, US patent application, 2005/6878837 B2. Process of Producing Alkyl Esters from Vegetable or Animal Oil and Aliphatic Monoalcohol.

[9] V. Pugnet, S. Maury, V. Coupard, A. Dandeu, A.-A. Quoineaud, J.-L. Bonneau, D. Tichit, Applied Catalysis A: General, 374 (2010) 71-78.

[10] C.T. Alves, A.S. de Oliveira, S.A.V. Carneiro, R.C.D. Santos, S.A.B.V.d. Melo, H.M.C. Andrade, F.C. Marques, E.A. Torres, Procedia Engineering, 42 (2012) 1928-1945.

[11] T.M. Sankaranarayanan, R.V. Shanthi, K. Thirunavukkarasu, A. Pandurangan, S. Sivasanker, Journal of Molecular Catalysis A: Chemical, 379 (2013) 234-242.

[12] J. Feng, L. Su, Y. Ma, C. Ren, Q. Guo, X. Chen, Chemical Engineering Journal, 221 (2013) 16-24. 
[13] M.A.E.A.A.A. El-Remaily, A.M. Abu-Dief, Tetrahedron, 71 (2015) 2579-2584.

[14] P. Jing, J. Li, L. Pan, J. Wang, X. Sun, Q. Liu, Journal of Hazardous Materials, 284 (2015) 163-170.

[15] K. Faungnawakij, N. Shimoda, T. Fukunaga, R. Kikuchi, K. Eguchi, Applied Catalysis A: General, 341 (2008) 139-145.

[16] K. Faungnawakij, N. Shimoda, T. Fukunaga, R. Kikuchi, K. Eguchi, Applied Catalysis B: Environmental, 92 (2009) 341-350.

[17] Z. Sun, L. Liu, D.z. Jia, W. Pan, Sensors and Actuators B: Chemical, 125 (2007) 144-148.

[18] S. Singh, B.C. Yadav, V.D. Gupta, P.K. Dwivedi, Materials Research Bulletin, 47 (2012) 3538-3547.

[19] Z. Xiao, S. Jin, X. Wang, W. Li, J. Wang, C. Liang, Journal of Materials Chemistry, 22 (2012) 16598-16605.

[20] C. Luadthong, S. Kuboon, C. Ratanatawanate, W. Nualpaeng, N. Viriya-Empikul, K. Faungnawakij, P. Pavasant, Science of Advanced Materials, 2016, doi:10.1166/sam.2015.2444.

[21] C. Despax, P. Tailhades, C. Baubet, C. Villette, A. Rousset, Thin Solid Films, 293 (1997) $22-28$.

[22] S. Saadi, A. Bouguelia, M. Trari, Renewable Energy, 31 (2006) 2245-2256.

[23] Z. Xing, Z. Ju, J. Yang, H. Xu, Y. Qian, Electrochimica Acta, 102 (2013) 51-57.

[24] S. Tao, F. Gao, X. Liu, O. Toft Sørensen, Materials Science and Engineering: B, 77 (2000) $172-176$.

[25] R.K. Selvan, C.O. Augustin, V. Šepelák, L.J. Berchmans, C. Sanjeeviraja, A. Gedanken, Materials Chemistry and Physics, 112 (2008) 373-380. 
[26] L.B. Zakiyah, E. Saion, N.M. Al-Hada, E. Gharibshahi, A. Salem, N. Soltani, S. Gene, Materials Science in Semiconductor Processing, 40 (2015) 564-569.

[27] O. Stefanescu, G. Vlase, M. Barbu, P. Barvinschi, M. Stefanescu, Journal of Thermal Analysis and Calorimetry, 113 (2013) 1245-1253.

[28] G.S. Henderson, F.M.F. de Groot, B.J.A. Moulton, Reviews in Mineralogy \& Geochemistry, 78 (2014) 75-138.

[29] V. Krishnan, R. K. Selvan, C. O. Augustin, A. Gedanken, H. Bertagnolli, The Journal of Physical Chemistry C, 111 (2007) 16724-16733.

[30] A.I. Frenkel, Q. Wang, N. Marinkovic, J.G. Chen, L. Barrio, R. Si, A.L. Cámara, A.M. Estrella, J.A. Rodriguez, J.C. Hanson, The Journal of Physical Chemistry C, 115 (2011) 1788417890.

[31] W. Nualpaeng, P. Tongprem, R. Keawmesri, N. Viriya-empikul, K. Faungnawakij, Fuel, 136 (2014) 240-243.

[32] K. Faungnawakij, B. Yoosuk, S. Namuangruk, P. Krasae, N. Viriya-empikul, B. Puttasawat, ChemCatChem, 4 (2012) 209-216. 
19 | P a g e

Table 1. BET surface areas, BJH pore sizes and pore volumes of samples.

\begin{tabular}{c|c|c|c}
\hline Catalyst & $\begin{array}{c}\text { BET surface } \\
\text { area } \\
\left(\mathrm{m}^{2} / \mathrm{g}\right)\end{array}$ & $\begin{array}{c}\mathrm{d}_{\mathrm{BJH}} \\
(\mathrm{nm})\end{array}$ & $\begin{array}{c}\text { Mesopore volume } \\
\left(\mathrm{cm}^{3} \mathrm{~g}^{-1}\right)\end{array}$ \\
\hline CuFe500 & 16.0 & 27.6 & 0.1319 \\
\hline CuFe700 & 2.1 & 3.6 & 0.0101 \\
\hline CuFe900 & $<1$ & 3.2 & 0.0024 \\
\hline
\end{tabular}


Table 2. Linear combination fitting of the calcined $\mathrm{CuFe}_{2} \mathrm{O}_{4}$ samples along with the Fe K-edge reference compounds

\begin{tabular}{|c|c|l|c|c|c|c|}
\hline Name & Absorption edge & \multicolumn{1}{|c|}{ Paths } & \% Weight & R-factor & $\chi^{2}$ & reduced $\chi^{2}$ \\
\hline CuFe500 & & $\mathrm{Fe}_{3} \mathrm{O}_{4}$ & $20.5 \pm 0.8$ & 0.000073 & 0.00835 & 0.0000633 \\
& & $\mathrm{Fe}_{2} \mathrm{O}_{3}$ & $13.9 \pm 1.2$ & & & \\
$\mathrm{CuFe}_{2} \mathrm{O}_{4}$ & $65.6 \pm 1.4$ & & & \\
\hline CuFe700 & & $\mathrm{Fe}_{3} \mathrm{O}_{4}$ & $16.7 \pm 0.8$ & 0.000067 & 0.00773 & 0.0000586 \\
& & $\mathrm{Fe}_{2} \mathrm{O}_{3}$ & $11.2 \pm 1.1$ & & & \\
$\mathrm{CuFe}_{2} \mathrm{O}_{4}$ & $72.1 \pm 1.3$ & & & \\
\hline CuFe900 & & $\mathrm{Fe}_{3} \mathrm{O}_{4}$ & $23.5 \pm 0.0$ & 0.000074 & 0.00842 & 0.0000638 \\
& & & & & & \\
\hline
\end{tabular}

$\mathrm{R}$-factor is a measure of the mean squared sum of the misfit at each data point

$\chi^{2}$ is the degree of misfit as the value of the measurement uncertainty

reduced $\chi^{2}$ is a factor of two, suggesting a substantive improvement in the fit quality 
Table 3. Obtained EXAFS structural parameters for the calcined $\mathrm{CuFe}_{2} \mathrm{O}_{4}$ catalysts

\begin{tabular}{|c|c|c|c|c|c|c|}
\hline Name & Paths & $\mathrm{N}$ & $\mathrm{R}(\AA)$ & $\sigma^{2}$ & $\Delta \mathrm{E}(\mathrm{eV})$ & F-factor \\
\hline \multirow[t]{5}{*}{ CuFe500 } & $\mathrm{Fe}-\mathrm{O}_{\text {tetra }}$ & 3.64 & 1.94 & 0.0059 & \multirow[t]{5}{*}{2.64} & \multirow[t]{5}{*}{$22.37 \%$} \\
\hline & $\mathrm{Fe}-\mathrm{Fe}_{\text {tetra }}$ & 10.37 & 3.03 & 0.0161 & & \\
\hline & $\mathrm{Fe}-\mathrm{O}_{\text {octa }}$ & 0.86 & 2.09 & 0.0011 & & \\
\hline & $\mathrm{Fe}-\mathrm{Fe}_{\text {octa }}$ & 4.88 & 3.49 & 0.0039 & & \\
\hline & $\mathrm{Fe}-\mathrm{Cu}_{\mathrm{octa}}$ & 1.28 & 3.46 & 0.0037 & & \\
\hline \multirow[t]{5}{*}{ CuFe700 } & $\mathrm{Fe}-\mathrm{O}_{\text {tetra }}$ & 2.04 & 1.88 & 0.0039 & \multirow[t]{5}{*}{3.44} & \multirow[t]{5}{*}{$18.62 \%$} \\
\hline & Fe-Fe $e_{\text {tetra }}$ & 9.41 & 3.04 & 0.0191 & & \\
\hline & $\mathrm{Fe}-\mathrm{O}_{\text {octa }}$ & 2.17 & 2.01 & 0.0056 & & \\
\hline & Fe-Fe $e_{\text {octa }}$ & 6.02 & 3.32 & 0.0032 & & \\
\hline & $\mathrm{Fe}-\mathrm{Cu}_{\mathrm{octa}}$ & 1.02 & 3.38 & 0.0032 & & \\
\hline \multirow[t]{5}{*}{ CuFe900 } & $\mathrm{Fe}-\mathrm{O}_{\text {tetra }}$ & 2.20 & 1.89 & 0.0031 & \multirow[t]{5}{*}{3.26} & \multirow[t]{5}{*}{$18.04 \%$} \\
\hline & $\mathrm{Fe}-\mathrm{Fe}_{\text {tetra }}$ & 9.39 & 3.03 & 0.0133 & & \\
\hline & $\mathrm{Fe}-\mathrm{O}_{\text {octa }}$ & 1.72 & 2.02 & 0.0060 & & \\
\hline & $\mathrm{Fe}-\mathrm{Fe}_{\text {octa }}$ & 11.61 & 3.27 & 0.0366 & & \\
\hline & $\mathrm{Fe}-\mathrm{Cu}_{\text {octa }}$ & 2.22 & 3.28 & 0.0041 & & \\
\hline
\end{tabular}

octa: atom backscatterers occupying the octahedral sites; tetra: atom backscatterers occupying the tetrahedral sites; N: coordination number; R: interatomic distance; $\Sigma$ : Debye-Waller factor with its calculated deviation; and $\Delta \mathrm{E}$ : Fermi energy deviation. 
Table 4. The leaching value of each catalyst as analyzed by the AAS technique.

\begin{tabular}{ccc}
\hline Catalyst & $\mathrm{Cu}^{2+}$ Conc. (ppm) & $\mathrm{Fe}^{3+}$ Conc. (ppm) \\
\hline CuFe500 & 3.3 & 33.8 \\
CuFe700 & 1.7 & 12.2 \\
CuFe900 & 1.6 & 14.6 \\
\hline
\end{tabular}




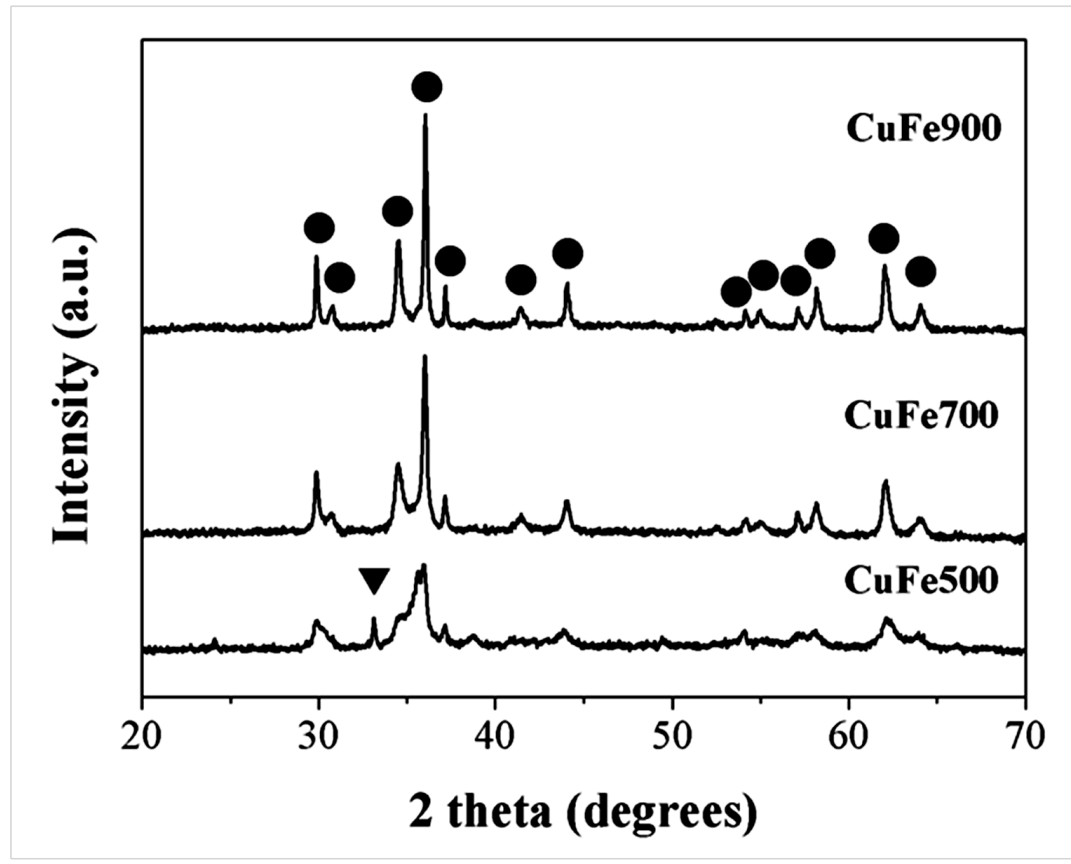

Fig. 1. XRD patterns of $\mathrm{CuFe}_{2} \mathrm{O}_{4}$ calcined for $4 \mathrm{~h}$ at 500 (CuFe500), 700 (CuFe700) and $900^{\circ} \mathrm{C}(\mathrm{CuFe} 900)$ : tetragonal $\mathrm{CuFe}_{2} \mathrm{O}_{4}(\mathbf{O})$ and $\mathrm{Fe}_{2} \mathrm{O}_{3}(\boldsymbol{\nabla})$. 

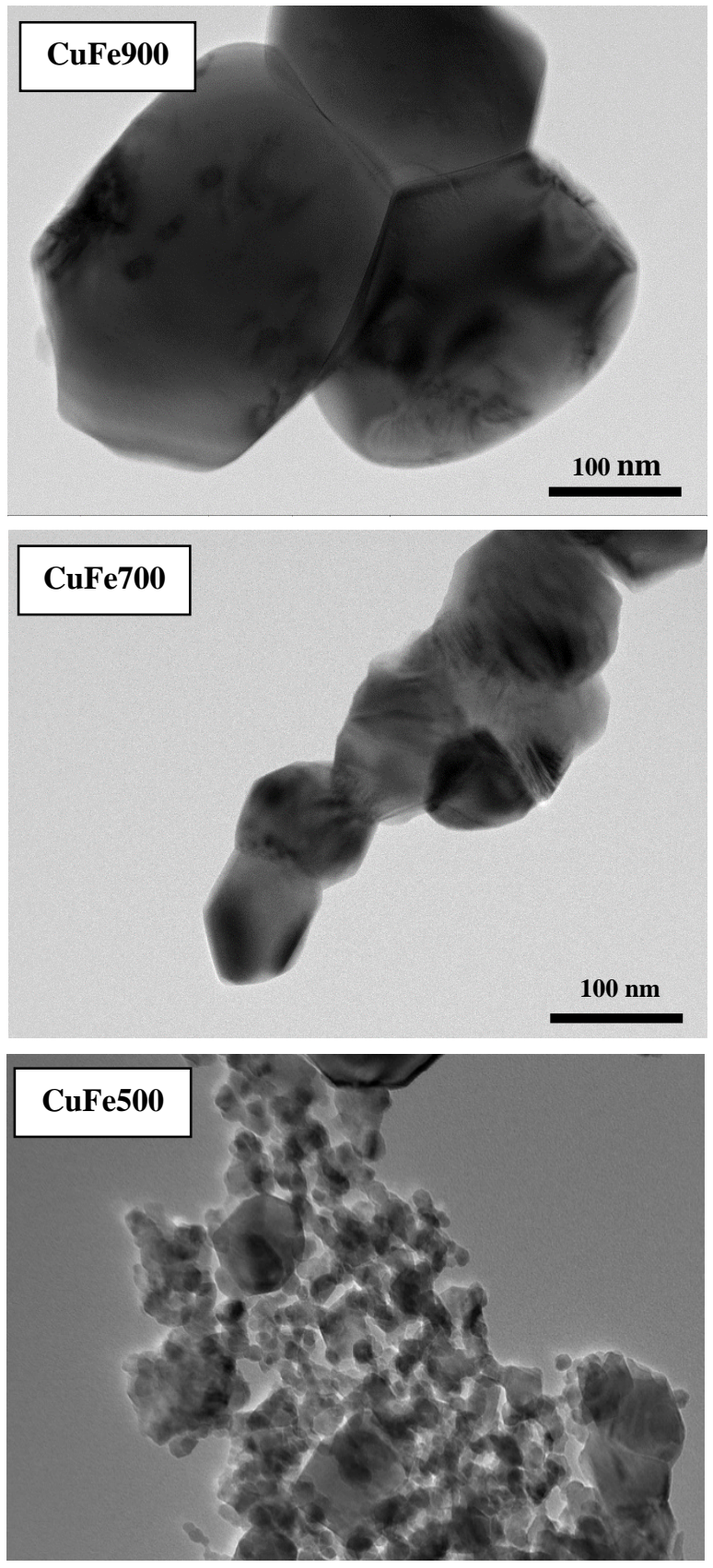

Fig. 2. TEM images of $\mathrm{CuFe}_{2} \mathrm{O}_{4}$ calcined for $4 \mathrm{~h}$ at 500 (CuFe500), 700 (CuFe700) and $900^{\circ} \mathrm{C}(\mathrm{CuFe} 900)$. 
25 | P a g e

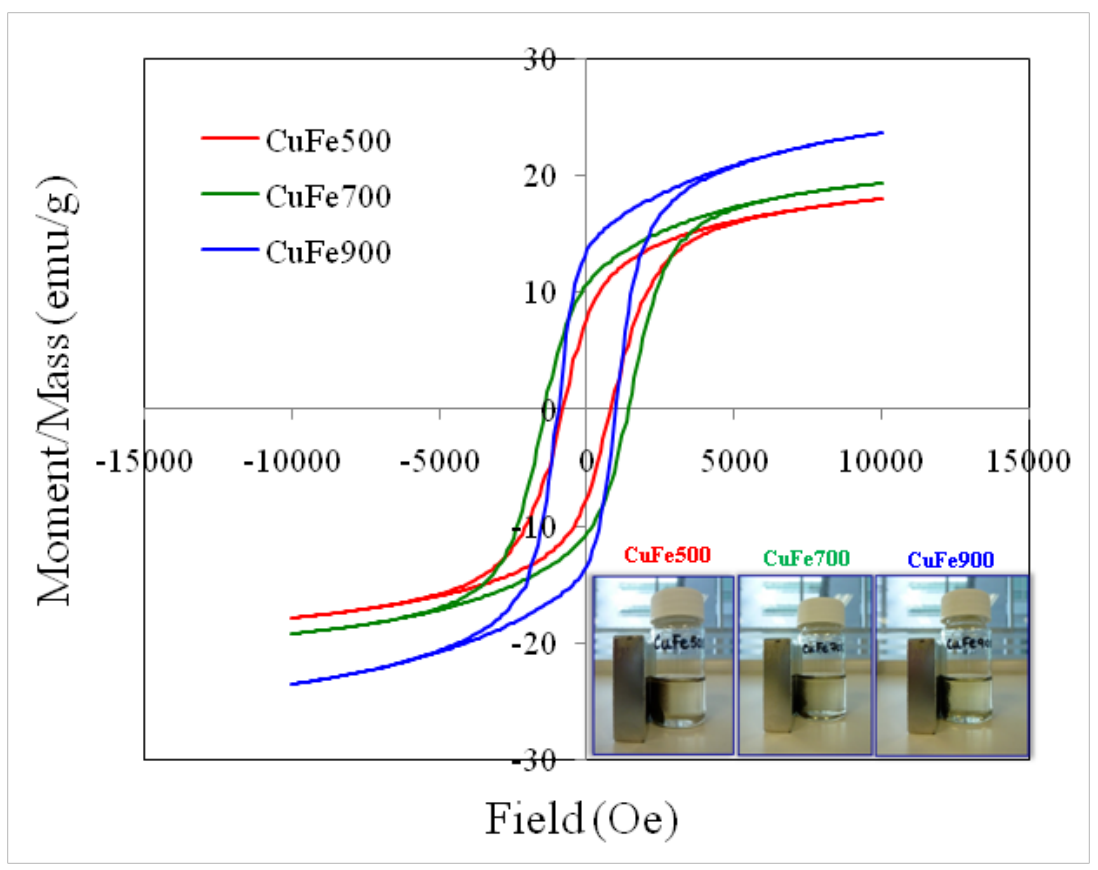

Fig. 3. Magnetic hysteresis loops of $\mathrm{CuFe}_{2} \mathrm{O}_{4}$ calcined for $4 \mathrm{~h}$ at 500 (CuFe500), 700 (CuFe700) and $900^{\circ} \mathrm{C}(\mathrm{CuFe} 900)$. 

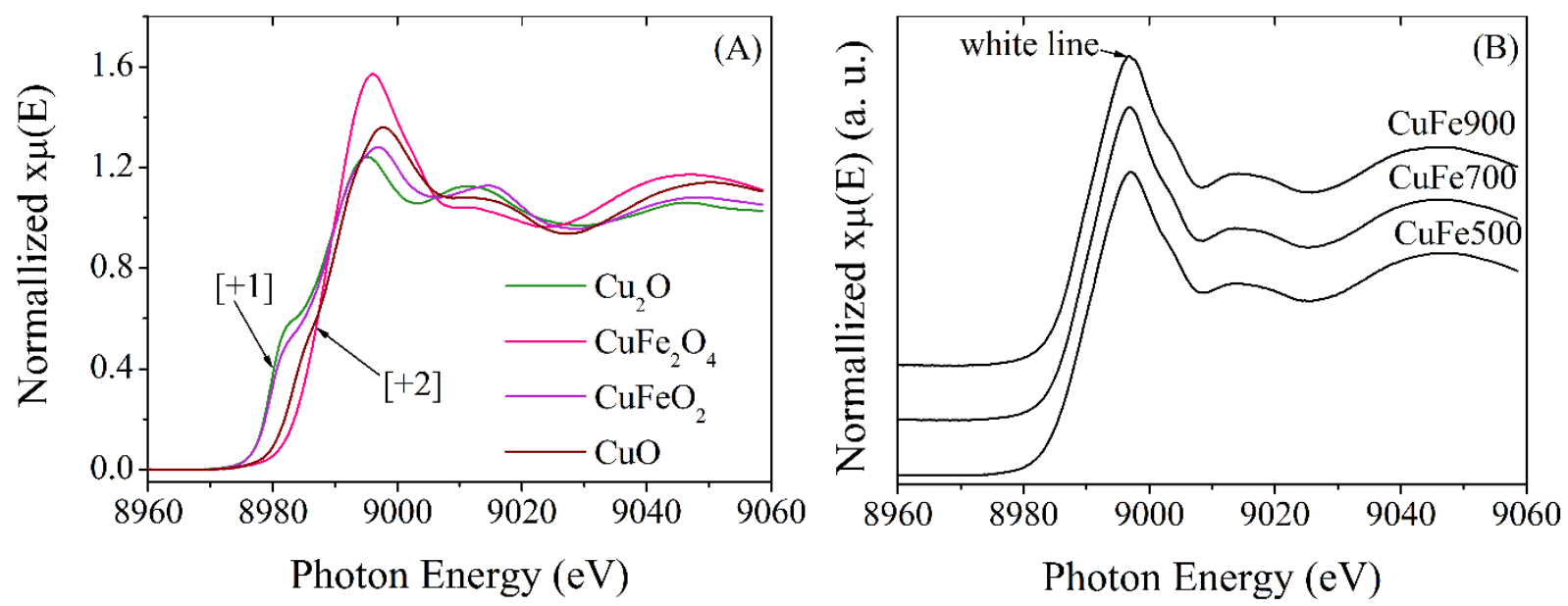

Fig. 4. Normalized XANES Cu K-edge spectra of standard copper oxides (A) and calcined samples (B) at 500 (CuFe500), 700 (CuFe700) and 900 $\mathrm{C}(\mathrm{CuFe} 900)$. 

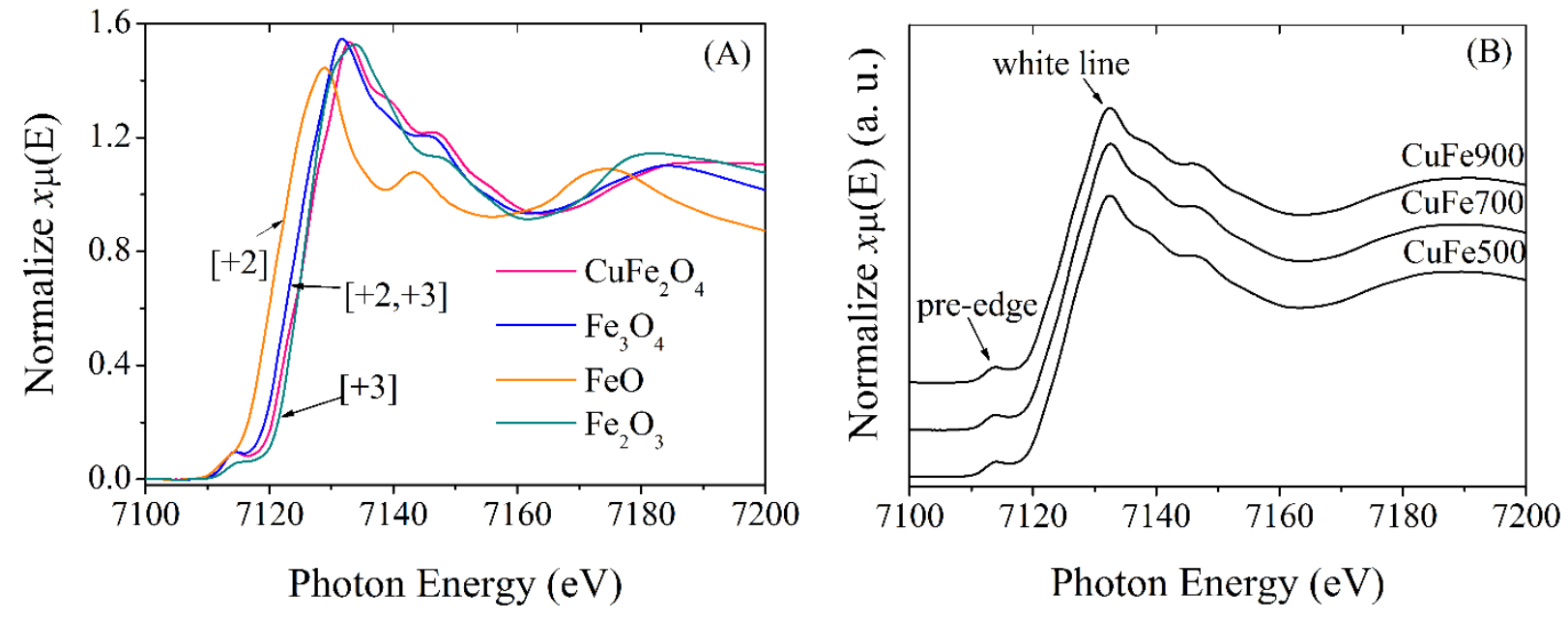

Fig. 5. Normalized XANES Fe K-edge spectra of standard iron oxides (A) and calcined samples (B) at $500(\mathrm{CuFe} 500), 700(\mathrm{CuFe} 700)$ and $900^{\circ} \mathrm{C}(\mathrm{CuFe} 900)$. 


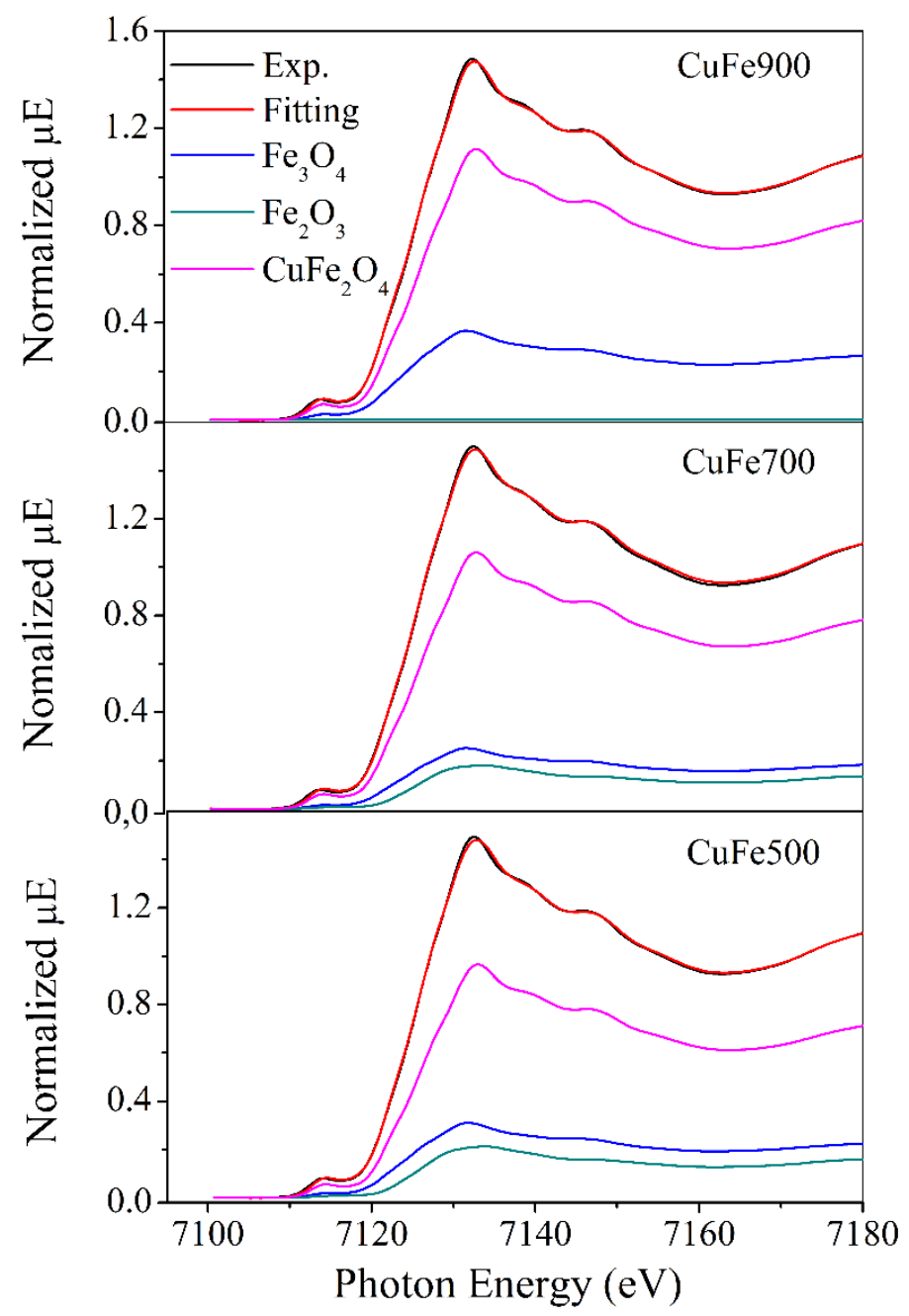

Fig. 6. Fits of the experimental spectra of the catalyst samples calcined for $4 \mathrm{~h}$ by linear combination fitting of the $\mathrm{Fe}_{2} \mathrm{O}_{3}, \mathrm{Fe}_{3} \mathrm{O}_{4}$ and $\mathrm{CuFe}_{2} \mathrm{O}_{4}$ spectra. 

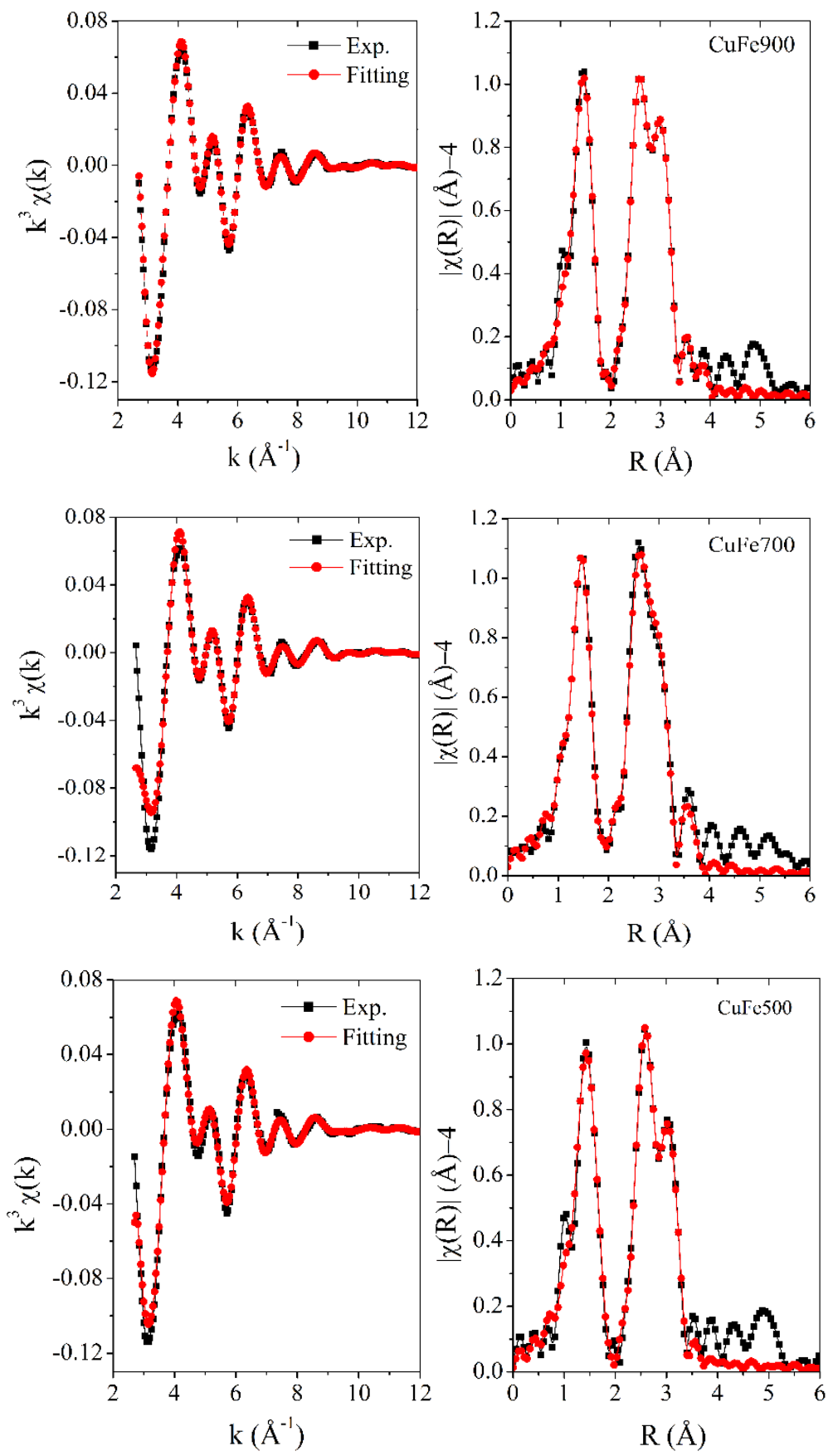

Fig. 7. EXAFS of $\mathrm{CuFe}_{2} \mathrm{O}_{4}$ calcined for $4 \mathrm{~h}$ at 500 (CuFe500), 700 (CuFe700) and $900^{\circ} \mathrm{C}$ (CuFe900). 


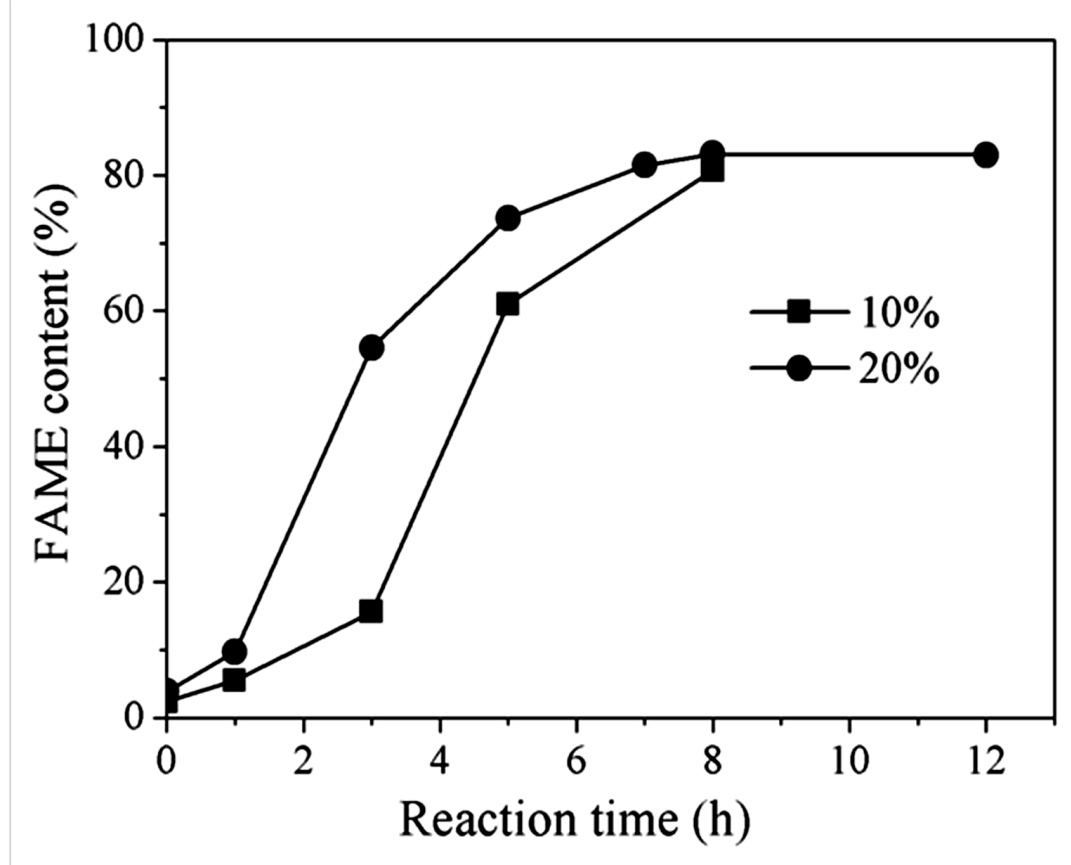

Fig. 8. Catalytic properties of transesterification on the CuFe700 catalyst with different amounts of catalyst loading. Reaction conditions: palm olein oil weight, 50 g; methanol/oil molar ratio, 9:1; and reaction temperature, $200^{\circ} \mathrm{C}$. 


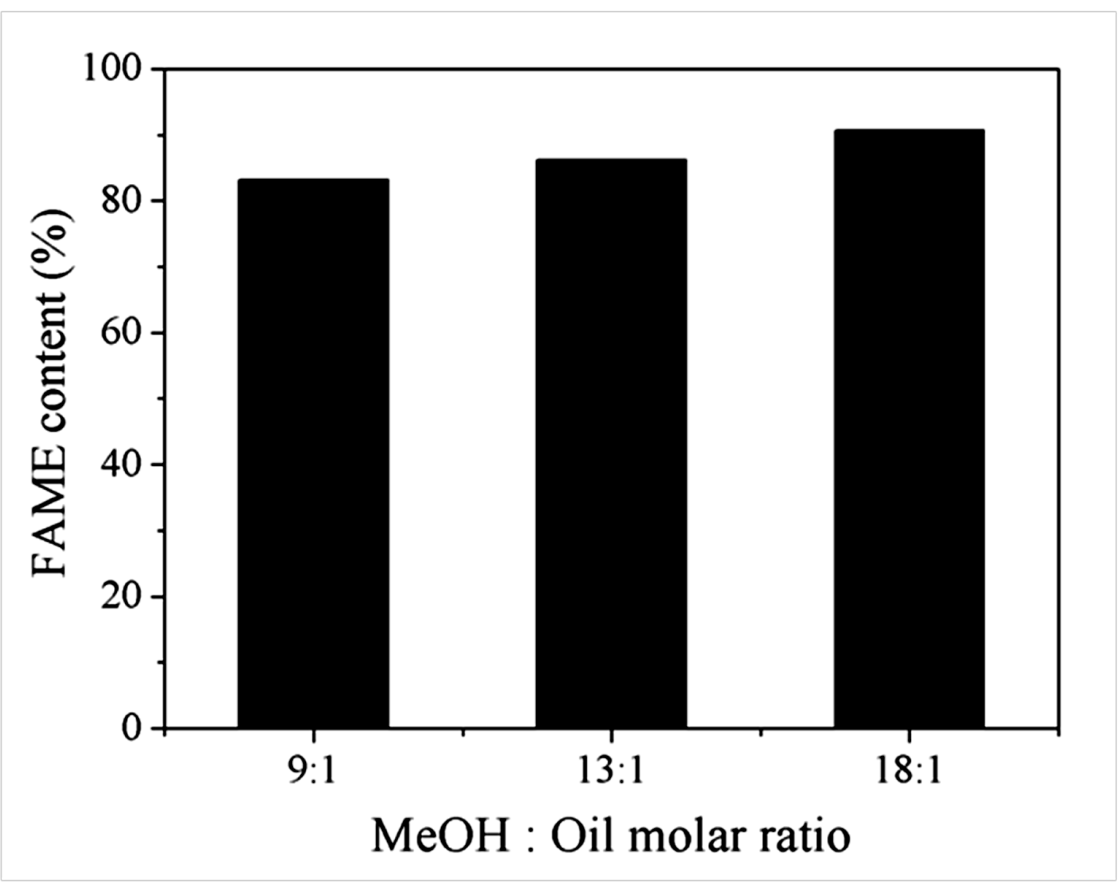

Fig. 9. Catalytic properties of transesterification on the CuFe700 catalyst with different molar ratios of oil to methanol. Reaction conditions: catalyst weight, $1 \mathrm{~g}$; palm olein oil weight, $50 \mathrm{~g}$; reaction temperature, $220^{\circ} \mathrm{C}$; and reaction time, $7 \mathrm{~h}$. 


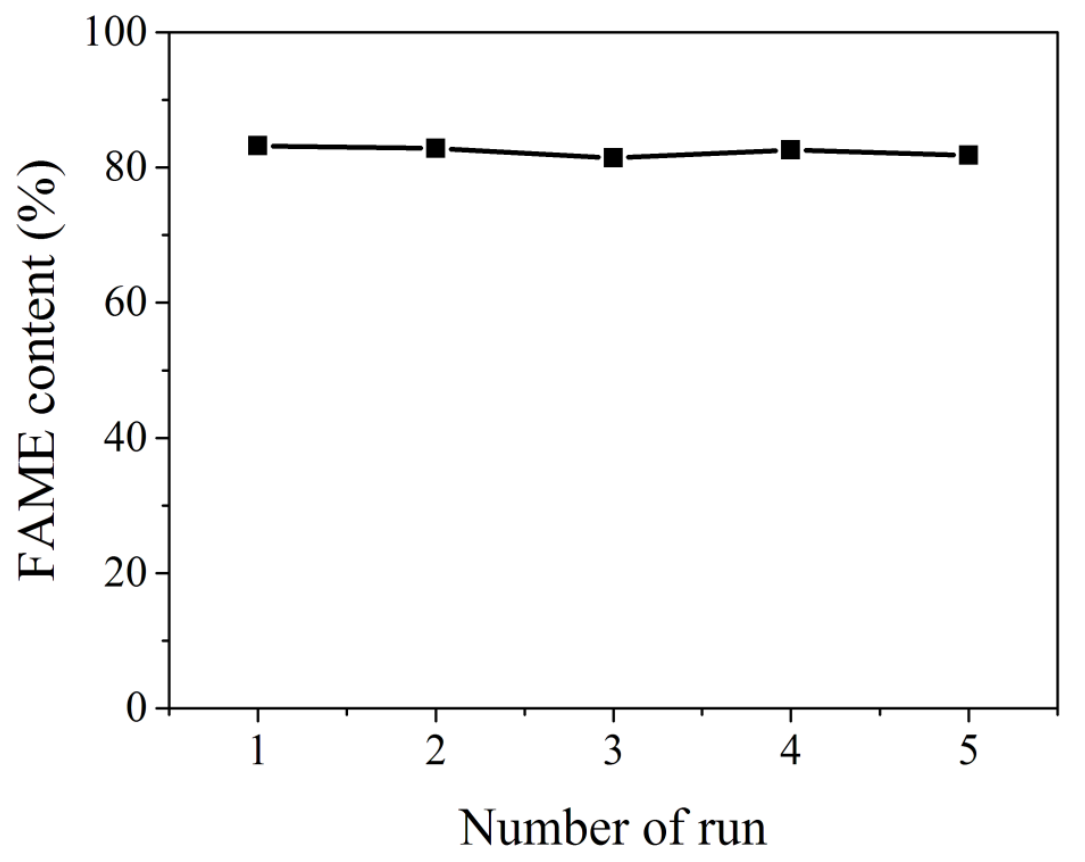

Fig. 10. \% FAME content of CuFe700 in five reaction cycles. Reaction conditions: catalyst weight, $1 \mathrm{~g}$; palm olein oil weight, $50 \mathrm{~g}$; methanol/oil molar ratio, 9:1; reaction temperature, $200^{\circ} \mathrm{C}$; and reaction time, $7 \mathrm{~h}$. 


\section{Graphical abstract}
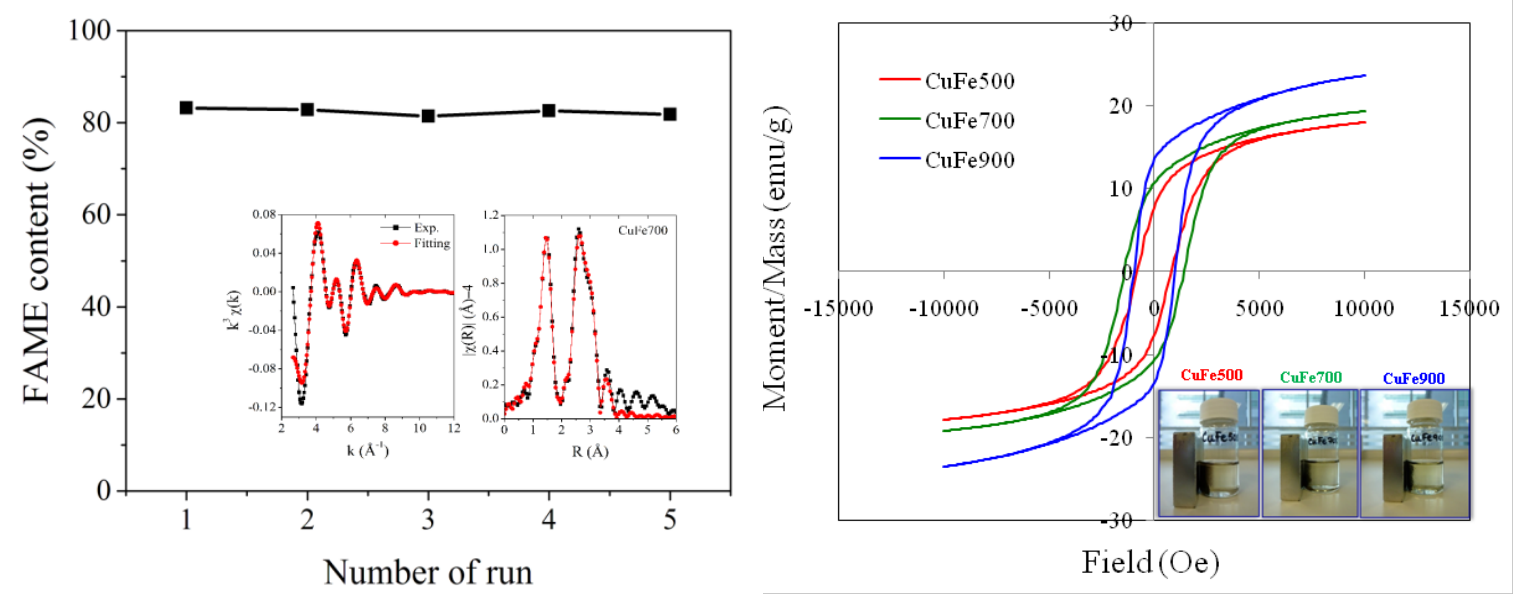